\title{
Influence of Western Feminist Literary Criticism on Chinese Feminine Writing
}

\author{
Tingting Zhang
}

Teaching and Research Institute of Foreign Languages, Bohai University, Jinzhou, 121013, China

tingting810905@163.com

Keywords: western feminist literary criticism; Chinese feminine writing; influence; effect

\begin{abstract}
Aim at western feminist literary criticism and the plight of female writing in China, this article guided by the feminist literary criticism theory system, the integrated use of the experience method, method of sociology, psychology, formalism method and the methods of comparative literature, puts forward that western feminist literary criticism on Chinese female writing effects include: "accept with western feminist literary theory with subverting the patriarchal discourse, promote the awakening of female self-consciousness and personal writing's development, achieve gender binary remove in the view of bisexual community and build hermaphrodite harmony, break through the Chinese female personalized writing and the warning place of female literary traditional construction, provide detailed practice of getting rid of elite trap and revealing spirit of introspection and self-renewal". This article from the perspective of contemporary women writers and readers, solve the problem of Chinese female literature theory and method of writing, to improve the level of Chinese female writing and promote the development of Chinese female literature.
\end{abstract}

\section{Introduction}

The function of literary criticism is to influence a writer's understanding and understand literary nature, characteristics and regularity, thus affecting the development of the creation, affect the readers of literature appreciation and understanding. Viewed from the history of historical materialism, humans after numerous rivalries and fusion of national culture, gradually developed to the mature of the national culture and regional culture, the strong vitality of the culture, it is a blend of many of the same or different cultural and vitality, out is the fate of the absorption and digestion. Viewed from the history of the dialectical materialism, any kind of national culture in the emergence and development process, always in constant and keeping, in a stable dynamic process. With other national culture at the same time, mutual communication and infiltration itself also in development, is a process of continuous screening [1,2]. This screening is the pursuit of national inside, sometimes the true; Sometimes in the alien culture directly beneath his gaze the dew-fogs dipped, and self reflection of cultural mechanism, to discard old culture, the development of the new culture. Play is the collision between Chinese and western culture in the new century and period, especially after the end of the cold war, western culture with aggressive streak, despising the Oriental culture. Chinese culture should take the initiative to dialogue with the western culture, mutual complementary interpretation in the dialogue, to achieve the cross-cultural creation and construction.

Through studying the western feminist literary criticism, break through the Chinese literary theory criticism for self sealing, recovery and international theory to great critical contact and communication, promoting China's literary criticism with international literary world and dialogue; To help China to deepen the understanding of literary critics, makes the Chinese literary theory criticism in an era of "symbiosis" diverse; Is conducive to China's literary theory criticism subservient to get rid of a subordinate to the political status, further strengthen the consciousness of literary theory criticism as a discipline and independent position. Through this article research, stressed human classic text, the anatomy of the male writer's female image reflects the male cultural mentality; Study the nature and characteristics of female writing, rebuild the body of the female 
writing, found the characteristics of the female literature; To find and establish a female literary tradition, overcome difficulties and women writing experience. Prompted Chinese scholars from literary creation to critical practice in the selective absorption, on the basis of western theories, combining with the characteristics of the local development of feminism literature and criticism has its own characteristics, to improve the level of Chinese female writing, and promote the development of Chinese female literature service.

\section{Accept with Western Feminist Literary Theory with Subverting the Patriarchal Discourse}

In western society culture, feminism is formed on the basis of which focus on individual's own all-round development, pay attention to human rights, freedom and equality. China has five thousand years of cultural tradition, the Confucian culture, national consciousness and the collective consciousness is dominant and to not pay attention to individual interests and personal development. To male authority as the standard of Chinese traditional culture, the male is the participants of the society and the masters of the family, women abandoned outside social life, the male in the family. Closed in thinking, women in the family, the narrow emotional world make their understanding of life often is based on the understanding of the male, the male of the hated also often expand as pessimistic about life. The loss of self's way of life, deeply influenced the Chinese women. To maintain a family, women choose to give up "individual liberation", female consciousness has yet to awaken [3].

As the old concept still rein in the writer's thinking, and be restricted by the traditional male discourse, Chinese female literature must accept a subvert the patriarchal discourse of western feminist literary theory if make a breakthrough. Thought liberation brought by the reform and opening to the outside world, in Chinese women's social participation and competitive at the same time, also make them start to history, reality and problems of its own profound reflection, accelerate the traditional patriarchal concept of resistance and the question of the feudal ethics. Although there is no vigorous feminist movement, also without radical slogan of western feminist literary theory, Chinese feminist literature is also working on this piece of virgin land, profoundly deconstructed the traditional male-centered discourse, become the centerpiece of the women's liberation in the new period.

Below the reflect that the figures in the western feminist literary theory, are the focus of attention to women themselves, dismantling and subverts the traditional male-centered discourse, open up the individual woman in public discourse space, form the background of writing the text and imagination. Position and individual words create distinct characteristics, female life ontology, writing women's bodies and desires, aroused the concern of the literary world. In the context of the current, the female writer writing personal life, and disclosure of personal privacy, attacks on male social and moral discourse, made gratifying results. Direct writing of women's personal experience, to the authority of the discourse and the male male society and men eager to female image of subversion." Personal writing" is therefore regarded as the main form of this period women writing, this is not only the western feminist literary theory and Chinese female literature creation of interaction between, also pay attention to the extension of feminist literature to explore the difference between the sexes.

\section{Promote the Awakening of Female Self-consciousness and Personal Writing's Development}

"Female writing" is a kind of can make women to get rid of Phallus center language writing, the practice of "female writing" will be closely linked with the body of women and desire, women's liberation and equality from the body's liberation and equality to [4-6]. As a famous slogan of western feminist literary creation, "body writing" is the body language to break the inequality in the narrative mode of writing. Conscious to the body as a direct result of a batch of refreshing literature. Into the $90 \mathrm{~s}$, a group of female writers is based on the real experience of the female body, the private experience into public cultural space, by female experience self read the bold table $\mathrm{v}$ and emotion, constantly subverts the traditional male-centered discourse as well as with male as the 
center of politics, history and the traditional concept of ethics.ith distinctive female standpoint and individual words, "body" should be brought into the language of narrative and ethical aesthetic category, in the literary world attention and controversy. Linbai's "One Man's War", from the perspective of the female body, from the hot and sexy area accurately depict, with multiple transformation of narrative and the structure of jumping, recorded the heroine explore the path of life and self-realization, strong vibration and controversy in the literary world, is the concrete practice of "body writing" in China.

Under the postmodern ideological trend and commercial capital, conspiracy, "body" is simplified as synonymous with sex and desire, "body writing" has become a sexual desire and vent channel; At the same time as the main body of the "body" and as consumption object into "body", it is difficult to draw a clear line, there are readers of literature misreading, does not rule out the author's subjective bad motives. Body and spirit is a contradictory unity of opposites, on behalf of the emotional, contingency and uncertainty of the body, and represent the spirit of rationality, necessity and certainty, unification on the basis of "body", if separate "mind and body" , with the body of irrational impulse, crazy and indulgence, to challenge mediocrity, depression, and a false reality cannot attain spiritual liberation. Female writing, therefore, in addition to the "body", also must have a noble soul; In addition to pay attention to personal space, also must have a sense of mission and sense of responsibility to the society; In addition to render personal spirit, also need to emphasize individuality. Only in this way, the female writing in order to achieve the real "free flight" state.

\section{Achieve Gender Binary's Remove in the View of Bisexual Community and Build Hermaphrodite Harmony}

Hermaphrodite, in biology is to point to the same individuals both mature male organ in your country, and has a mature female sex organs; In body structure and physiological characteristics, characterized by a mixture of male and female. In psychology, refers to the same individuals are both obvious male personality characteristics, but also has obvious female personality traits, both tough and tender, decisive and meticulous character. In feminist thinkers view, the "hermaphrodite" represents a kind of feminist values and personality ideal. Because in the mechanism of the patriarchal culture, the woman is unlikely to be equal status with men. Feminist thinker use "hermaphrodite" to reflect a kind of transcendence of other opposition, at the same time perfect fusion between men and women of outstanding quality of the concept of "human" [7, 8].

The French feminist theorists west Sue said: "bisexual" namely " everyone found in their own gender, the existence on the basis of individual men and women, with significantly varied resolute". "hermaphrodite" with the feminist movement, in the challenge to the traditional male position and thinking, in the interpretation of feminist poetic evolution in different colors. "Bi" myth is broken, but through the modern interpretation of feminist poetic, closer "people". "Myth" in the process of reaching "words", the myth of thinking and concept of feminist poetic from afar to maintain contact with an invisible spirit, this is the "perfect complementary bisexual culture" of the human will never stop the pursuit of the ideal. "hermaphrodite" is not only the ideal relationship, is also the writer's best. Between the sexes should be tolerance and respect, eliminate the opposition, to freedom and equality.

Harmony hermaphrodite, including two layers of meanings: one is that aroused hide in the excellent quality of male and female body of the opposite sex; two is to integrate the excellent quality of female and male body, at the same time to integrate the excellent quality of male to female body, so as to realize "harmony hermaphrodite". Man of feminine and women of masculine" not emphasize quality for women to attract men, but the human qualities together with the ideal of humanity. Neither simple symmetry between men and women, is not a party to the other side of the rule or beyond". Chinese women writers should jump out of the "hermaphrodite" the western concept, the use of "harmony hermaphrodite", from the height of the cultural and political, more "harmonious", more sincere, more tolerance, less the alienation of human nature, less infighting between the sexes. Female literature gradually out of the single emotional and love, heaven and 
earth, at a higher level with male discourse community, to reach the ideal of "harmony hermaphrodite" literature.

\section{Break Through the Chinese Female Personalized Writing and the Warning Place of Female Literary Traditional Construction}

French feminist Cixous in such aspects as breakthrough of the women's boldness and taboo, inspired writers to explore the courage of the body. But Cixous theory has a clear orientation, the female body is covered by time and culture of desire, through the body, to abandon the patriarchal veiled, let a woman express herself. But when the localization of the theory of "radical" deviated from the revolutionary nature, only keep language shell, it is difficult to achieve the objectives of the feminist book. Private women experience and the body, not women seek success, "the private life of others, no matter what time, leak details reveal others life, all involves ethical issues". Couldn't feel without sharp feminist standpoint, the women in the culture and history of depression, unable to make the female writing in literary criticism there are differences between the "voice", finally also is unable to avoid the end of the female writing is integrated in the patriarchal system.

In the $1990 \mathrm{~s}$, the transformation of social and cultural context from single to multiple, showing a flourishing literary landscape, female writing enter prosperous period, women become the pronoun of female literature "personalized writing". But as women "personalized writing" naked desire to become market-oriented, entered from the deep to the plight of vulgar. Women "personalized writing" crisis [9]. Mr Hooks feminist standpoint, to reflect on the contemporary Chinese female personalized writing predicament is of great enlightenment, if turned into a drain the private writing, has lost its original intention, also does not make women in the field of social life and spiritual liberation, it eliminated the "body" of infinite complexity of richness and diversity, into the trap of male desire, is used by the patriarchal culture.

Chinese women writers and scholars on the concept of "female literature" of the deviation has been questioned, Zhangjie said of what is a female literature: "writing the woman's problem or the writer is a woman, or give the women in the works of melodramatic? Some works show off women's melodramatic, don't treat women literature problem objectively, so the concept of female literature is vague. Some Chinese women writers to female literature norm within the framework of make public the women's liberation, whether to have "female consciousness" as the division standard, is helpful to discover by the patriarchal culture buried women writers and works." Women's consciousness" is the center of the research on women, women's literature criticism standard.China's female consciousness under the influence of equality in the west, with the bourgeois democracy thought produced and developed, are women speak with words.

\section{Provide Detailed Practice of Getting Rid of Elite Trap and Revealing Spirit of Introspection and Self-renewal}

The development of modern western women literature backward position to deconstruct modern culture, inadvertently turned the once upon a time a relatively narrow gender politics and natural gender angle of view, the aesthetic modernity from becoming one of the few elite's patent, deeper into the public society. Therefore, about the feminine literature development between internal imbalance, began to involve in the west. The public perspective of the western feminist literary criticism, inspired the Chinese female writing from elite trap at an early date. The contemporary Chinese women can freely engage in writing, this is the result of external identity "liberated". When writing endless theme, multiple perspectives and personal style, etc., the knowledge and ideas are elite trap. Away from social reality scene pieces written and privacy of female literary discourse, female readers do not know why.

The development of the modern western feminist literature, will not become a small number of elite's patent, but expect further mass society, and reversed the previous relatively narrow natural gender perspective and gender politics. Feminism is the by-product of the male democracy 
movement, are the oppressed men against the world inside a man is not equal [10]. British and American feminist literary criticism, from the male democratic movement in the inheritance of resistance, is on the premise of gender awareness, on the meaning of the Chinese female writing is free-standing self-improvement spirit. Free-standing self-improvement is the power of women on their own standing in society, standing in front of men, make men to women sit up and take notice. The contradiction between family and career is a female in the new period introspection self-renewal spirit reveals the main contradiction.

"The patriarchal demanding more" in the form of social pressure, women in a dual role: on the one hand, the social system ensure that women and men enjoy the same employment opportunities, achieve equal pay for equal work; In social consciousness and conception, on the other hand, women all basically followed the traditional patriarchal values, as the smallest group of families, women are still in the role of labor. Women under double pressures, as do the traditional wife and mother, and must strive for personal economic independence and social status. The completeness of the British and American feminist literary criticism resisting, shall be for the Chinese women show the principles of introspection self-renewal spirit.

\section{Conclusion}

The western feminist literary criticism has also had a huge influence on Chinese contemporary female literature. Influenced by British and American, Chinese literary world split out the difference between the male literary female literature, female writers say goodbye to the asexual era of literature, women's self-reliance spirit began to reveal. Accept subvert the patriarchal discourse significance of western feminist literary theory. Because of the old ideas are still rein in the writer's thinking, coupled with the influence of the traditional male discourse, Chinese female literature creation to make a breakthrough, subvert the patriarchal discourse significance to accept a western feminist literary theory is particularly important; To promote the awakening of female self-consciousness and personal writing. New century female literary creation shows a tendency of diversified development, women's subject consciousness of exploring and also in a variety of ways, both in the new period of the Chinese literary world harvest, also pushed Chinese female literature creation into the new stage; In the perspective of community of bisexual achieve gender binary digestion and construction of gender harmony. Chinese women writers should jump out of the "hermaphrodite" the concept of westernization, out of a single emotional and love, heaven and earth, at a higher level with male discourse community, to reach the ideal of "harmony hermaphrodite" literature; Break through the Chinese female personalized writing and the precinct of women's literary tradition. Sisu's comments on the body writing in the body writing phenomenon discussion cited frequency of unsurpassable, unlocked the courage, boldness and breakthrough of as taboo, exemplary, also inspired writers have the courage to explore the body; Provide from elite trap and introspection self-renewal spirit. The public perspective of the western feminist literary criticism inspired the Chinese female writing from elite trap at an early date. British and American feminist literary criticism, from the male democratic movement in the inheritance of resistance to the meaning of the Chinese female writing is free-standing self-improvement spirit.

\section{Acknowledgement}

This work is supported by social science fund project of Liaoning province (L15CWW001): Western Feminist Literary Criticism and Its Influence on Chinese Female Writing.

\section{References}

[1] Azadeh Mehrpouyan, Seyedeh Samereh Abbasnezhad Banehmir, "Feminism and Feminine Culture in Modern Women Writers' Works: With Special Reference to Anne Sexton and Audre Lorde," Procedia - Social and Behavioral Sciences, vol. 158, no. 19, pp. 199-205, 2014. 
[2] G. Y. Guan, "A review of Western Feminist Literary Criticism," Overseas English, vol. 16, no. 2, pp. 3-4, 2015.

[3] Z. L. Zhang, "Western Literature of Feminism and the Development of Chinese Literature of Feminism," Journal of Xi'an Shiyou University (Social Science Edition), vol. 14, no. 3, pp. 72-76, 2005.

[4] X. Chen, "On the localization of Western Feminist Literary Theory in China," Master's degree of Yanan University, 2012.

[5] Helena Forsås-Scott, "From concept of woman studies to gendered texts: Feminist literary criticism in Sweden[J]. Women's Studies International Forum, , vol. 18, no. 2, pp. 223-233, 2015. 2015, 18(2): 223-233.

[6] H. P. Li, "Body Writing in Chinese and Western Cultural Context," Journal of Gansu Normal Colleges, vol. 19, no. 6, pp. 29-31, 2014.

[7] H. Jiang, "Two yuan opposition and Deconstruction of gender: a study of the development of Western feminist literary theory," Master's degree of Northwest University, 2009.

[8] J. Chen, "'Double body' and Woolf's Feminist Narrative," Master's degree of East China Normal University, 2008.

[9] C. Wu, "Plight and Breakthrough of Chinese Women's 'Personalized' Writing: Reflection on Chen Ran's Literary Creation," Journal of Anhui Radio \& TV University, vol. 12, no. 4, pp.

[10] Y. L. Wu, "The influence of British and American feminist literary criticism on Chinese contemporary female writing," Flying Apsaras, vol. 62, no. 18, pp. 14-15, 2011. 